\begin{tabular}{|c|c|c|}
\hline $\begin{array}{l}\text { PKS } \\
\text { PUBLIC } \\
\text { KNOOLEDGE } \\
\text { PROJECT }\end{array}$ & $\begin{array}{c}\text { REVISTA DE GEOGRAFIA } \\
\text { (RECIFE) } \\
\text { http://www.revista.uffe.br/revistageografia }\end{array}$ & $\begin{array}{l}\text { OJS } \\
\frac{\text { OPEN }}{\text { JOUNAL }} \\
\text { SYSTEMS }\end{array}$ \\
\hline
\end{tabular}

\title{
GEOMORFOLOGIA E PLANEJAMENTO AMBIENTAL - CONCEITOS E APLICAÇÕES
}

\author{
Antonio Jose Teixeira Guerra ${ }^{1}$ \\ ${ }^{I}$ Professor Titular do departamento de Geografia da Universidade Federal do Rio de Janeiro - UFRJ. Email: \\ antoniotguerra@gmail.com
}

Artigo recebido em 15/04/2018 e aceito em 16/05/2018

\begin{abstract}
RESUMO
Esse artigo tem como objetivo investigar o papel da Geomorfologia e outras ciências, no planejamento ambiental. Dessa forma, diversos artigos, capítulos de livros e teses de doutorado foram pesquisados, para apresentar uma revisão da literatura, como apoio aos conceitos e aplicações relacionados a esse assunto. $\mathrm{O}$ planejamento ambiental é fundamental, porque é quase impossível atingir desenvolvimento urbano sustentável, sem levar em conta a paisagem e os recursos naturais. A partir do momento que a Geomorfologia está preocupada com o estudo das formas de relevo, solos, rochas e os processos que originaram as formas de relevo, é fundamental que os planejadores considerem esses aspectos, quando se quer implementar políticas públicas para o crescimento urbano. Além disso, a Geomorfologia tem sido inserida em novos conceitos que tem emergido nas geociências como geodiversidade, geoconservação e geoturismo. Outras áreas onde a Geomorfologia tem papel fundamental, estão relacionadas ao turismo, exploração de recursos minerais, produção de energia hidrelétrica, saneamento básico, Unidades de Conservação, áreas costeiras, bacias hidrográficas, Estudos de Impactos Ambientais (EIAs), avaliação de áreas degradadas, estudos de movimentos de massa e erosão dos solos, e recuperação de áreas degradadas.
\end{abstract}

Palavras-chave: Geomorfologia, Planejamento ambiental, Crescimento urbano, Conceitos, Aplicações

\section{GEOMORFOLOGY AND ENVIRONMENTAL PLANNING - CONCEPTS AND APPLICATIONS}

\begin{abstract}
This paper aims at investigating the role of Geomorphology and other sciences, in environment planning. For that, several papers, chapters and $\mathrm{PhD}$ theses have been searched, to present a comprehensive literature review to support the concepts and applications related to this subject. Environmental planning is fundamental, since it is nearly impossible to achieve sustainable urban growth without considering the landscape and natural resources used for that. Since Geomorphology is concerned with the survey of landforms, soils, rocks and the processes which have originated these landforms, it is fundamental for planners to consider all these aspects, when one must implement public policies for urban growth. In addition, Geomorphology plays an important role also in other aspects, especially considering geotourism, geodiversity and geoconservation. Other areas where Geomorphology has a fundamental role, are related to tourism, mineral resources exploitation, hydroelectric energy production, basic sanitation, Conservation Units, coastal areas, drainage basins, environmental impact assessment, degraded areas assessment, mass movement and soil erosion studies, and land recuperation.
\end{abstract}

Keywords: Geomorphology, Environmental planning, Urban growth, Concepts, Applications. 


\section{INTRODUÇÃO}

A Geomorfologia tem tido, cada vez mais, aplicação em diversos campos de conhecimento, em especial no Planejamento Ambiental, que é o tema a ser abordado nesse artigo. Enquanto alguns cientistas procuram entender o planeta Terra, os geomorfólogos estão preocupados com as interações de uma grande variedade de fatores que controlam a dinâmica da superfície terrestre, incluindo o papel das atividades antropogênicas (Alcántara-Ayala, 2010). Consequentemente, o volume e a qualidade das pesquisas relacionadas à prevenção de desastres, desenvolvidas por geomorfólogos, tem se ampliado bastante, nos últimos anos. Este é apenas um exemplo da infinidade de aplicações que a Geomorfologia pode ter no mundo moderno

Esse tema vem sendo discutido por pesquisadores de diversas áreas do conhecimento. Um bom exemplo disso é o livro editado pela geógrafa inglesa Janet Hooke, intitulado Geomorphology in Environmental Planning (1988), no qual Martin Haigh fez uma interessante revisão, publicada em 1989, na Transactions of the Institute of British Geographers. Nessa análise, Haigh (1989) destaca que os geomorfólogos têm habilidades que são vitais para os planejadores ambientais, no sentido de poderem reduzir os riscos de impactos ambientais, e ao mesmo tempo, podem predizer os efeitos ambientais de determinadas políticas públicas. Na Grã-Bretanha, até a época que o livro foi publicado, Haigh (1989) chama atenção que os geomorfólogos contribuíram pouco nesse sentido. Bem como, segundo o autor acima, esses profissionais têm que competir com grandes empresas de engenharia e agências governamentais, que dominam o mercado. Haigh (1989) termina sua análise, enfatizando que o livro proporciona um grande suporte para aqueles que querem seguir na temática relacionada à aplicação da geomorfologia no planejamento ambiental.

A Geomorfologia é o estudo das formas de relevo, levando em conta os processos formadores, bem como os materiais envolvidos - solo e/ou rocha. Seu conhecimento é fundamental, para que possa ser bem aplicada ao planejamento ambiental, com o objetivo de reduzir, ou evitar as catástrofes que têm assolado várias partes do mundo, geralmente com dezenas, ou centenas de mortes, bem como perda de recursos naturais, muitas vezes de forma irreversível. Guerra e Marçal (2015), chamam atenção, que através dos estudos relacionados às encostas, canais fluviais, áreas costeiras, processos cársticos, geleiras, desertos, e outros, 
tem sido possível melhorar a qualidade de vida das populações, bem como preservar e conservar ambientes naturais, e aqueles transformados pelo homem.

Esse artigo examina as interações entre Geomorfologia e políticas públicas. A preocupação é com efeitos sobre as paisagens físicas e os processos que agem sobre as mesmas. Temos que nos preocupar, não apenas com as políticas atuais, mas também as necessidades futuras, a partir da aplicação de determinadas políticas, em relação ao meio ambiente. A Geomorfologia se preocupa com os processos atuantes na superfície terrestre. Dessa forma, qualquer atividade que modifique as formas de relevo, induzem movimentação de materiais, ou alteram a quantidade e qualidade de água e a rede de drenagem, onde estão situadas. Muitas atividades podem afetar, indiretamente, as propriedades da superfície terrestre, através de interações com a cobertura vegetal. A propósito disso, Hooke (1988) afirma que os seres humanos vivem, trabalham e têm seu lazer, sobre a superfície terrestre, e tais atividades inevitavelmente produzem mudanças nos ecossistemas terra-água. Dessa forma, os geomorfólogos têm interesse especial nas atividades desenvolvidas pela sociedade, que produzem modificações sobre os processos naturais.

Algumas das mudanças geomorfológicas são resultado de alterações de larga escala, na superfície terrestre, como as escavações feitas pela mineração. Em outros casos, os resultados mais óbvios de uma atividade, ou política pública, pode ser estética e ecológica, e, as mudanças geomorfológicas são mais sutis. Questões de políticas públicas que provoquem impactos nas paisagens, podem ser consideradas em termos dos principais tipos de atividades humanas, zonas geomorfológicas, ou esferas políticas (Hooke, 1988). A propósito disso, a referida autora destaca que na Grã-Bretanha, nas últimas décadas, do século XX, as políticas públicas nas áreas rurais, têm causado as maiores mudanças no uso da terra. A mudança no tipo de agricultura, com maior impacto, em especial nas planícies, com aumento da produção de cereais, e incentivos para aumento no uso intensivo das terras, tem levado à remoção das cercas das propriedades, drenagem de áreas alagadas, levando ao aumento da erosão dos solos, afetando a quantidade e qualidade de água. Isso tudo se reflete no aumento do assoreamento dos corpos líquidos.

Algumas atividades, de caráter rural ou urbano, que são dinâmicas, do ponto de vista geomorfológico, apresentam problemas específicos, e devem também ser analisados. $\mathrm{Na}$ grande maioria das vezes, esses problemas ocorrem, devido à falta de planejamento ambiental, e políticas públicas, que é o tema desse artigo. A multiplicação de órgãos públicos, que fiscalizam essas atividades, pode também contribuir para a ocorrência dos impactos aqui 
analisados. Mas não são apenas mudanças morfológicas, que podem ser significantes, que devem ser analisadas, mas também alterações de processos e mudanças na qualidade da água. Os problemas geomorfológicos podem ser examinados, em termos de tipos específicos de áreas, como por exemplo, aquelas reconhecidas pela legislação, sendo, portanto, protegida por política pública e planejamento ambiental, como os Parques Nacionais e Estaduais, no Brasil. Outras Unidades de Conservação (UCs) são também amparadas por legislação, mas muitas vezes não são fiscalizadas, repercutindo em diversos tipos de impactos (Fig. 1).

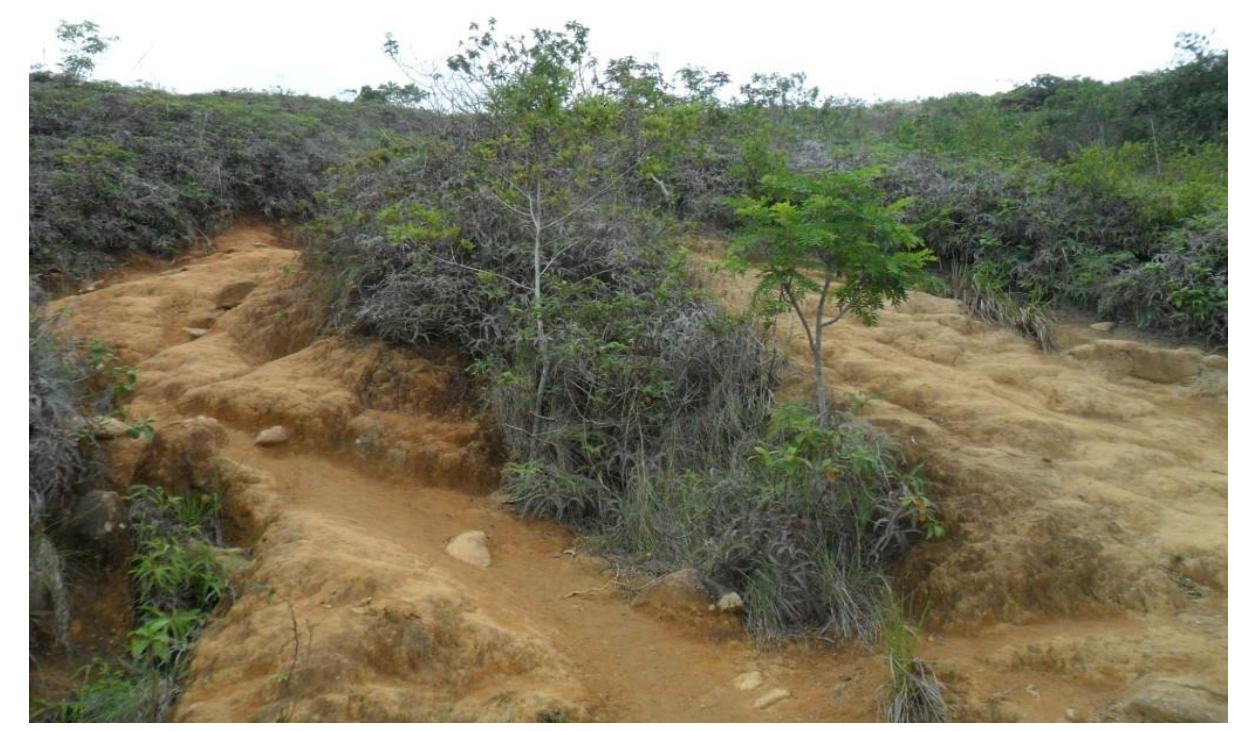

Fig. 1. Processo erosivo acelerado na Reserva Ecológica da Juatinga, município de Paraty, Rio de Janeiro. Foto: Luana de Almeida Rangel (2013).

Em muitas partes do mundo, o rápido processo de urbanização tem causado diversos tipos de impactos às sociedades e ao meio ambiente. Para combater esses tipos de impactos, muitas cidades têm introduzido diferentes tipos de políticas públicas. No entanto, o uso da geomorfologia no planejamento ambiental não tem sido tarefa fácil para os administradores (Perveen et al., 2017). Para facilitar essa tarefa, os autores aqui citados propõem um método de planejamento, que se baseia em cenários que produzem diferentes visões para o crescimento urbano, de maneira sustentável, ao incorporar diversas abordagens socioambientais. Dessa forma, Perveen et al. (2017) chamam atenção das dificuldades de criar modelos de crescimento urbano, associados aos impactos que esses cenários podem proporcionar, para fortalecer e quantificar o futuro das políticas urbanas, relacionadas com o planejamento ambiental. A maioria dos temas incluem incertezas associadas com a seleção de métodos e de indicadores apropriados para gerar cenários, bem como podem ser priorizados 
na formulação de políticas públicas e, finalmente, avaliar impactos dos diferentes cenários, sobre as políticas propostas, para o crescimento das cidades.

Dessa forma, esse artigo aborda conceitos relacionados à Geomorfologia aplicada ao planejamento ambiental, bem como estudos de caso, no Brasil e em outros países, de forma a aprofundar uma ciência que vem, cada vez mais, sendo utilizada para melhorar a qualidade de vida e a prevenção a impactos causados pela má utilização dos recursos naturais, tanto em áreas urbanas, como rurais.

\section{CONCEITOS}

Esse item aborda alguns conceitos fundamentais, no que diz respeito à aplicação da Geomorfologia ao planejamento ambiental, que vem ganhando força no Brasil e no mundo, destacando a importância que a Geomorfologia vem tendo em trabalhos acadêmicos e na sua aplicação técnica. A propósito disso, Guerra e Marçal (2015) chamam atenção dos diversos autores que vêm abordando esse tema: Abrahams (1986), Morgan (1986 e 2005), Cooke e Doornkamp (1977 e 1990), Hooke (1988), Goudie (1990), Goudie e Viles (1997), Fullen e Catt (2004), Lima-e-Silva et al. (2004), Marçal e Guerra (2004), Guerra et al. (2017). Essa lista tem aumentado, sendo abordada no presente artigo.

Quando analisamos a Geomorfologia aplicada ao planejamento ambiental, é importante destacar que a Geomorfologia Ambiental, abordada em Guerra e Marçal (2015), "surge a partir do reconhecimento do papel da ação do homem nos processos geomorfológicos, e na evolução das formas de relevo, ou seja, o homem agindo como um agente geomorfológico" (p. 21, Guerra e Marçal, 2015). Dessa forma, é fundamental o reconhecimento das formas de relevo, solos, rochas, recursos hídricos, etc. Isso pode levar ao melhor conhecimento da paisagem geomorfológica e, consequentemente, do aproveitamento racional dos recursos existentes, bem como torna possível evitar catástrofes, que quase sempre causam mortes e danos materiais.

Um conceito fundamental, que devemos destacar logo de início, refere-se ao planejamento ambiental, que é um dos focos desse artigo. A propósito disso, Haughton (2017) aborda muito bem esse tema, quando afirma que envolve, tanto sistema de planejamento legal, como sistemas de gestão ambiental mais amplos, tais como qualidade da água, riscos de enchente e de deslizamento. $\mathrm{O}$ planejamento ambiental opera em diferentes escalas, desde as locais, como as regionais, levando em conta diferentes abordagens. 
Refletindo seu papel na interface entre as diferentes formas de planejamento legal e não legal, do ambiente, uma preocupação central é a necessidade de reconhecer e lidar com diferentes características geográficas e político-administrativas (Haughton, 2017).

Ainda com relação ao trabalho de Haughton (2017), o autor destaca que o planejamento ambiental envolve a aceitação, ou negação de direitos de desenvolvimento, para uma determinada área, consequentemente, segundo o referido autor, possui uma componente política, na medida que se refere à redistribuição de poder e recursos. Isso sempre aconteceu, mas tem sido trazido à tona, mais recentemente, por trabalhos ligados à ecologia política urbana. Essa estrutura leva à conclusão que o planejamento ambiental, longe de ser uma ciência neutra, envolve sempre um ato político, envolvendo a redistribuição de vencedores e perdedores.

Outros dois autores que vêm trabalhando com essa temática são Papageorgiou e Gemennetzi (2017), onde afirmam que o espaço verde urbano é de vital importância para as cidades, aumentando a qualidade de vida e mantendo desenvolvimento sustentável. Importante também é o fato de o planejamento ambiental assegurar benefícios para os residentes, na medida que reconcilia preocupações ambientais com aspirações sociais e econômicas. Os referidos autores destacam, que no caso da Grécia, o aumento de espaços verdes legais nas cidades de Atenas e Tesalônica, deram ênfase ao planejamento metropolitano, reformado recentemente. Embora o planejamento ambiental na Grécia tenha sido inspirado em abordagens do ponto de vista ecológico, a implementação de espaços e infraestrutura verdes, tiveram sucesso parcial, devido à própria peculiaridade da evolução histórica das cidades gregas. A crise econômica que a Grécia tem vivido nos últimos anos, torna ainda mais difícil manter espaços vazios verdes, nas cidades, ou seja, esses espaços, na maioria das vezes, têm sido transformados em áreas construídas, o que gera renda e emprego, num país que tem atravessado uma séria crise.

Papageorgiou e Gemennetzi (2017) apontam ainda que numa cidade como Atenas, a proporção de áreas verdes é muito abaixo dos $5 \mathrm{~m}^{2} /$ habitante, e bem abaixo dos padrões para outras cidades gregas, que é de $8 \mathrm{~m}^{2} /$ habitante. Ao mesmo tempo, os espaços verdes são distribuídos de forma desigual na região metropolitana de Atenas, porque a proporção de área verde é bem pequena no centro histórico da cidade, ao contrário das áreas suburbanas, ao norte e sul da capital grega.

No Brasil existem também diversos pesquisadores trabalhando sobre essa perspectiva. O planejamento ambiental adequado é fundamental para a estabilidade e manutenção da 
estrutura dos ecossistemas. As atividades humanas podem alterar a dinâmica de conservação da biodiversidade, podendo repercutir em danos aos serviços ecossistêmicos (Pires et al., 2016). Os mapeamentos são de grande importância nesse tipo de trabalho. A propósito disso, Pires et al. (2016, p. 901), afirmam que "os dados gerados no mapeamento do uso e ocupação da terra são indispensáveis nas práticas de planejamento e gestão ambiental do município em diferentes escalas, auxiliando as tomadas de decisões para o zoneamento territorial, visto que esses dados retratam as atividades humanas que podem influenciar negativamente os elementos naturais".

Pelo fato de compreenderem os sistemas geomorfológicos, não apenas no tempo, mas espacialmente falando, os geomorfólogos são capazes de predizer riscos ambientais, de processos e locais, dentro dos sistemas, em uma grande variedade de escalas espaçotemporais (Crozier e Glade, 2010). Os referidos autores destacam ainda que os geomorfólogos deveriam estar aptos a identificar os hotspots, dentro dos sistemas, as mudanças que os mesmos podem sofrer, onde e quando os limiares intrínsecos e extrínsecos podem ser alcançados, e o mais importante, como esses limiares podem mudar, no tempo e no espaço.

O emprego da Geomorfologia no planejamento ambiental possui uma série de implicações conceituais, que devem ser abordadas, quando se deseja utilizar essa ciência, de forma adequada, com o máximo de aproveitamento dos conceitos, métodos e técnicas utilizadas para reduzir, ou pelo menos evitar riscos e perigos ambientais. Os autores Crozier e Glade (2010) abordam muito bem esses conceitos. A propósito disso, chamam atenção da importância das características dos processos geomorfológicos, que os tornam perigosos, incluindo uma grande variedade de parâmetros: volume (massa), velocidade, profundidade, mecanismos, duração e extensão areal. A relevância e capacidade de produzir danos, que podem estar relacionados a esses parâmetros, varia com o tipo de perigo, a magnitude da intensidade desses parâmetros, na época em que acontecem, e a frequência com a qual os danos são esperados, em um dado local.

Crozier e Glade 2010) apontam que infelizmente apenas alguns desses parâmetros críticos são registrados com base em dados históricos, de maneira sistemática, que possam ser de utilidade na avaliação do risco ambiental. Por exemplo, enchentes podem ter um bom registro de seu pico de descarga, mas poucos são os dados sobre a duração das enchentes, que pode ser mais importante, no que diz respeito às perdas econômicas. Os referidos autores destacam ainda que a análise de frequência-magnitude, que pode ser considerada o centro da avaliação de perigo, está quase sempre restrita a representações convencionais de magnitude, 
como volume de material dos deslizamentos, total de precipitação, descarga das enchentes, em vez de parâmetros que retratem com mais precisão o dano potencial do perigo.

Mais recentemente, a geomorfologia aplicada ao planejamento ambiental, vem sendo cada vez mais utilizada em temas relacionados ao geoturismo, geodiversidade, geoconservação, patrimônio geológico e geomorfológico. Ela pode ter papel fundamental na conservação e no desenvolvimento econômico de uma determinada área. A propósito disso, Jorge e Guerra (2016), afirmam que os conceitos discutidos e analisados por diferentes pesquisadores, nos últimos anos, têm dado grande avanço à geodiversidade e geoconservação, levando ao desenvolvimento de um turismo sustentável. Diversos autores nacionais e internacionais têm abordado esse tema, de maneira clara e objetiva (HOSE, 1995 e 2012; BRILHA, 2005 e 2016; SANTUCCI, 2005; MOREIRA e BIGARELLA, 2008; MOREIRA, 2008; MORA FILHO e RUAS, 2008; MANSUR, 2009; DOWLING, 2010; GODINHO et al., 2011; KUBALIKOVÁ, 2013; MOREIRA, 2014; FARSANI et al., 2012, 2014; OLLIER, 2012, NASCIMENTO et al, 2015; JORGE e GUERRA, 2016; JORGE et al., 2016; PALHARES e GUERRA, 2016; JORGE, 2017; RANGEL, 2018).

A partir dos conceitos aqui apresentados, uma série de exemplos de aplicações são feitas, nesse artigo, com o objetivo de caracterizar diversas maneiras de como a geomorfologia aplicada ao planejamento ambiental, pode ser de grande valia, no desenvolvimento sustentável, tanto em áreas urbanas, como rurais.

\section{APLICAÇÕES}

Esse item aborda diversas maneiras de como a Geomorfologia pode ser aplicada ao planejamento ambiental. A literatura geomorfológica tem mostrado, nos últimos anos, que tem se multiplicado o seu papel, no sentido de poder ser empregada, para diagnosticar, mas principalmente, para prognosticar como promover o desenvolvimento sustentável, de uma determinada área, quando o planejamento adequado, leva em consideração conceitos e aplicações proporcionados pela Geomorfologia.

Alterações ambientais, devido à ação humana, sempre ocorreram na superfície terrestre, mas isso tem acontecido a taxas cada vez mais elevadas, nas últimas décadas. Além disso, à medida que a população cresce e os recursos naturais diminuem, a pressão sobre os recursos restantes, aumenta (Hooke, 1988). É reconhecido que pode haver consequências negativas sobre o meio ambiente, se o crescimento desordenado ocorre, e as taxas continuam 
aceleradas. A combinação desses fatores, junto com o conhecimento do meio ambiente, tem gerado maior preocupação com as questões ambientais. Isso tem levado ao aumento considerável da literatura geomorfológica, relacionada a esses temas. Alguns dos argumentos têm sido econômicos, mas a tendência é de incorporar os custos ambientais, na avaliação de projetos. Dessa forma, a legislação exigida, em muitos países da União Europeia, bem como nos Estados Unidos, já está em operação (Hooke, 1988). Isso tem ocorrido no Brasil, há algumas décadas, através da necessidade da elaboração dos EIAs-RIMAs, para determinados tipos de intervenção no meio ambiente. Esse é mais um exemplo da geomorfologia aplicada ao planejamento ambiental.

Nessa abordagem, há que se considerar também as mudanças climáticas. A propósito disso, Hill (2016) argumenta que objetivos, conceitos e métodos relacionados ao emprego da geomorfologia no planejamento urbano, têm tido grande avanço nos últimos anos. Diversos trabalhos têm surgido, sendo que para Hill (2016), a maioria deles está relacionada a demandas da prática corrente, em vez de propostas teóricas. Essa nova literatura tem surgido também para lidar com questões relacionadas às mudanças climáticas. Hill (2016) propõe ainda que tem surgido um novo paradigma no planejamento ambiental urbano, com o objetivo de proteger a biodiversidade da urbanização, assim como planos que procuram proteger as cidades contra enchentes e deslizamentos, e, mais recentemente, contra tendências de aumento do nível do mar, que pode também estar relacionado às mudanças climáticas.

Ciências aplicadas, como a engenharia, economia, política, geografia e estudos ambientais, têm sido inspirado, crescentemente, pela escola de ecologia humana, dos perigos naturais (Hufschmidt e Glade, 2010). No final da década de 1970, o conceito de vulnerabilidade foi implementado para pesquisa em energia, gestão de risco e avaliação de impacto climático. Modelos de colapso social e ecologia foram combinados sob o guardachuva da vulnerabilidade. As ciências aplicadas definem vulnerabilidade como o grau de perda, que pode ser expressado com uma taxa de dano (por exemplo de 0 a 1). Isso é baseado nas definições da Organização das Nações Unidas para Prevenção de Desastres. A análise de vulnerabilidade pode ser feita de forma qualitativa, semi-qualitativa e quantitativa. $\mathrm{Na}$ avaliação geral da avaliação do risco, as descrições qualitativas são geralmente usadas, como uma primeira abordagem, para identificar diferentes aspectos da vulnerabilidade, ou quando dados numéricos não estão disponíveis (Hufschmidt e Glade, 2010).

Um bom exemplo de como a Geomorfologia pode ser aplicada aos estudos de vulnerabilidade, refere-se aos riscos de deslizamentos. As escalas de análise variam desde as 
detalhadas, locais, até as regionais. A vulnerabilidade a deslizamentos é geralmente considerada para indivíduos, em relação às construções e ruas, levando em conta o caminho preferencial dos deslizamentos (Figs. 2 e 3).

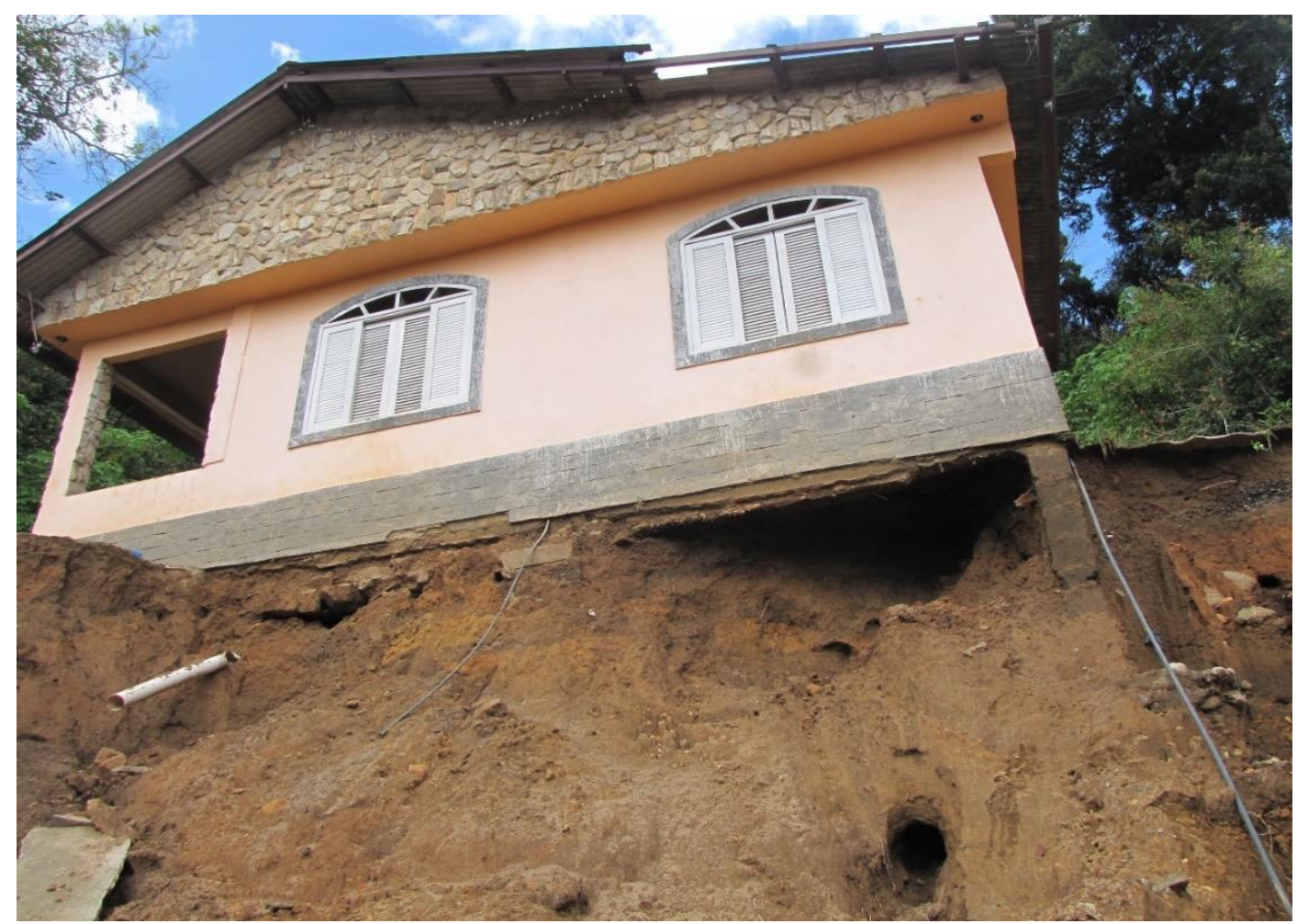

Fig. 2.Cicatriz de deslizamento, com casa condenada, no bairro do Quitandinha (Petrópolis, RJ), devido a fortes chuvas ocorridas em abril de 2013. Foto: Antonio Jose Teixeira Guerra.

Quase sempre, quando se analisa a vulnerabilidade aos deslizamentos, os seguintes fatores devem ser levados em conta: localização do elemento em risco; componente temporal; impacto causado pelo deslizamento; velocidade e profundidade do deslizamento; e finalmente, as estruturas dos elementos que estão em risco.

Uma aplicação dessa metodologia é a avaliação de risco para a ocorrência de deslizamento, implementada pelo Projeto Australiano de Geociências das Cidades, com relação a algumas comunidades urbanas. A vulnerabilidade de pessoas, construções e vias de comunicação é expressa pela probabilidade de perda fatal, ou destruição, colocada numa escala de 0 a 1 (Michael-Leiba et al., 2003 e 2005).

Uma aplicação importante da geomorfologia ao planejamento ambiental é aquela reportada por Parkey (2015), onde o autor aponta quatro formas de aplicação, com informação espacial, baseada no uso de SIG de alta qualidade: 1. Identificação de áreas florestais, com fins à sua conservação; 2. Monitoramento da saúde ecológica de áreas úmidas, com invasão 
de espécies; 3. Planejamento para o desenvolvimento em um corredor de rio urbano; 4. Mapeamento de espécies raras e ameaçadas de extinção, numa determinada paisagem.

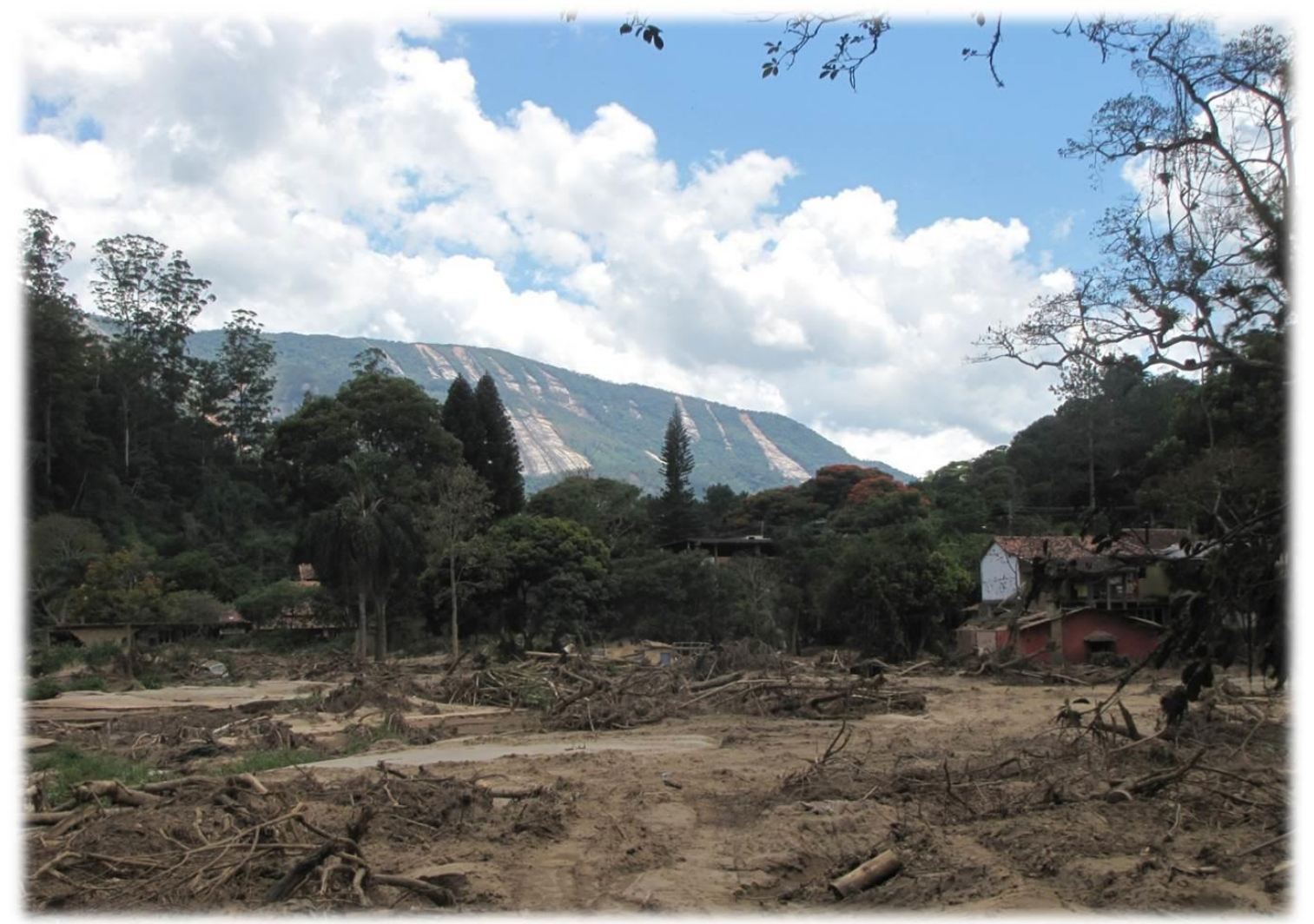

Fig. 3. Cicatrizes de deslizamentos nas encostas e planície degradada pelos movimentos de massa, ocorridos no vale do rio Cuiabá, durante as catástrofes ocorridas em janeiro de 2011, no município de Petrópolis. Foto: Antonio José Teixeira Guerra.

De acordo com Haughton (2017), quando se fazem aplicações da geomorfologia ao planejamento ambiental, há que se considerar esse planejamento como uma disciplina que continua a evoluir, refletindo os debates sociais, no sentido de melhorar o conhecimento ambiental dos relacionamentos sociedade-natureza. Essa evolução é importante porque elas têm influenciado nas ações em áreas urbanas e rurais, por mais de um século. Dessa forma, o planejamento ambiental tem atraído o interesse dos geógrafos, e ainda segundo Haughton (2017), há um considerável grau de inter-relacionamento de ideias entre a geografia e o planejamento, levando-se em conta o debate acadêmico e a prática em si. Nos últimos anos, o crescente interesse da política no desenvolvimento sustentável, tem auxiliado no interesse do planejamento ambiental. Isso é comprovado pelo sistema de planejamento do Reino Unido, que em 2004 foi criado um regimento legal, com o propósito de apoiar o desenvolvimento 
sustentável, reforçando a importância do debate sobre sustentabilidade no planejamento ambiental.

A propósito disso, Guerra e Marçal (2015) apontam a importância do conhecimento geomorfológico, em relação à abordagem dos sistemas físicos, porque as atividades desenvolvidas na superfície terrestre estão sempre sobre alguma forma de relevo e algum tipo de solo. Ou seja, esse conhecimento, além de poder evitar a ocorrência de impactos ambientais sobre o ambiente, pode auxiliar no tão propalado desenvolvimento sustentável, a que se refere Haughton (2017). Ou seja, o estudo geomorfológico de uma determinada área, quando se planeja o seu desenvolvimento, pode ser de grande valia para que não ocorram impactos ambientais negativos. Nesse sentido, Guerra e Marçal (2015) apresentam uma série de exemplos da importância da geomorfologia no planejamento ambiental, como: turismo, exploração de recursos minerais aproveitamento de recursos hídricos, produção de energia hidrelétrica, saneamento básico, Unidades de Conservação, áreas costeiras (Fig. 4), EIAsRIMAs, diagnóstico de áreas degradadas, estudos de movimentos de massa e erosão dos solos (Fig. 5), linhas de transmissão de energia elétrica, e recuperação de áreas degradadas.

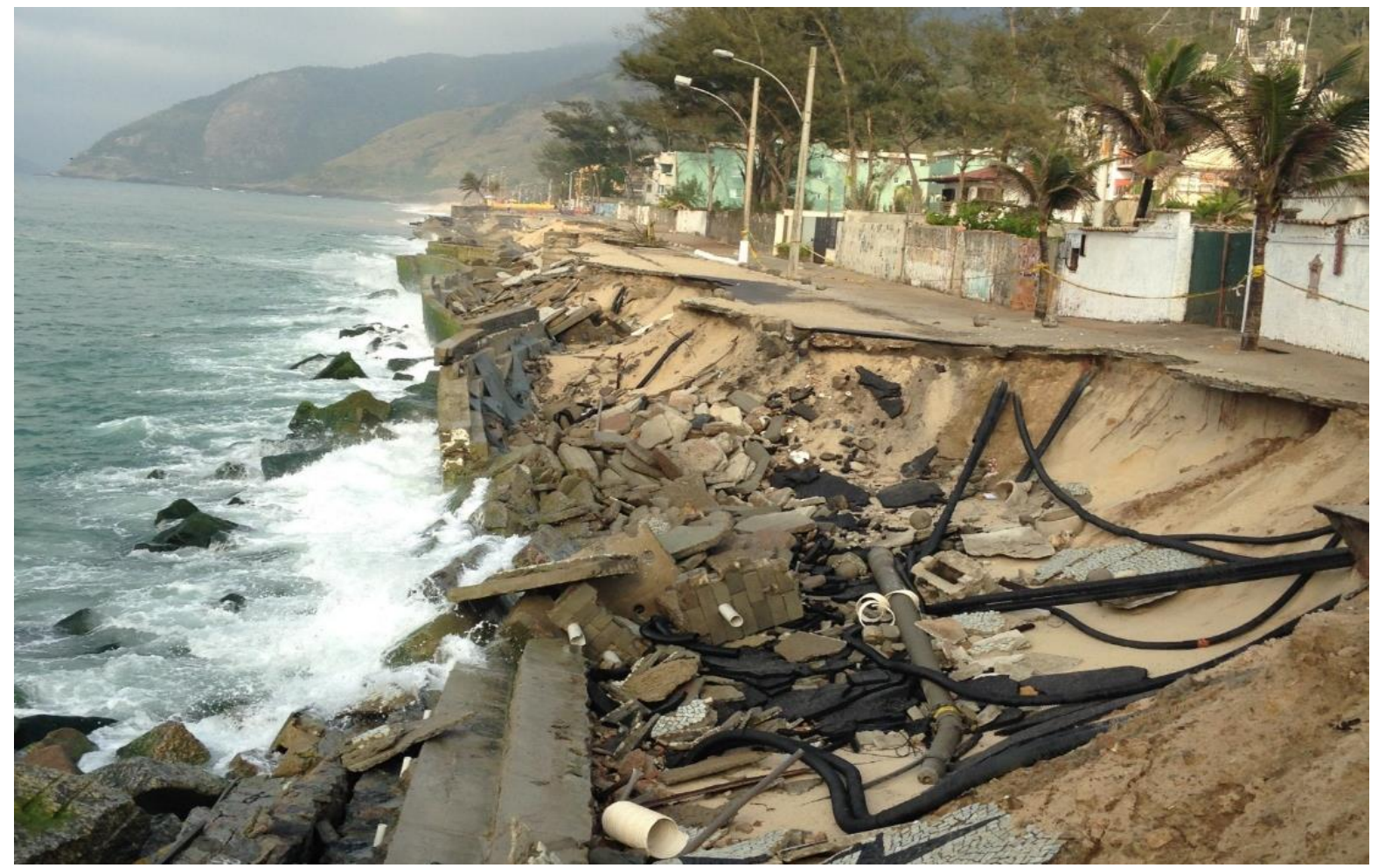

Fig. 4. Erosão costeira na Praia da Macumba, Rio de Janeiro, RJ, em outubro de 2017. Foto Antonio José Teixeira Guerra 


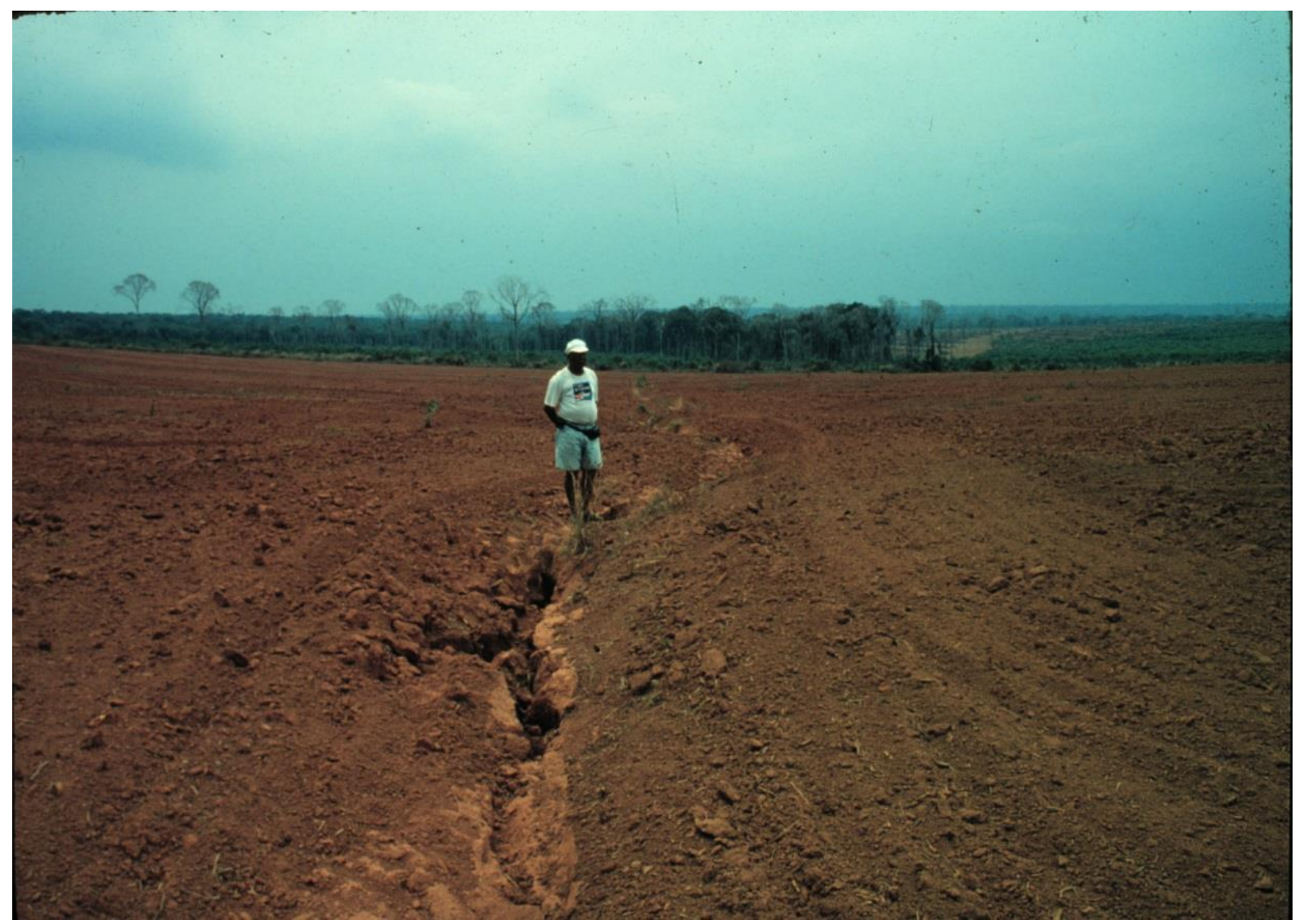

Fig. 5. Ravina em área de convergência de fluxo em Sorriso - MT

Mais recentemente, a geomorfologia tem sido também aplicada a tópicos, como geodiversidade, geoturismo e geoconservação. A propósito disso, Jorge e Guerra (2016) dão uma série de exemplos, das bases conceituais proporcionadas pela geomorfologia, no que diz respeito à "geodiversidade, patrimônio geológico-geomorfológico e o papel do geoturismo como um novo segmento do turismo sustentável e, por fim, a importância da geoconservação, seja na escala global ou local, como um novo paradigma voltado à sustentabilidade” (p. 152). Os referidos autores chamam ainda atenção dos trabalhos acadêmicos, nas Geociências, aí incluída a Geomorfologia, é claro, para a divulgação da geodiversidade e sua geoconservação, bem como o geoturismo, como atividade econômica aliada à conservação dos ambientes naturais (Fig. 6). 


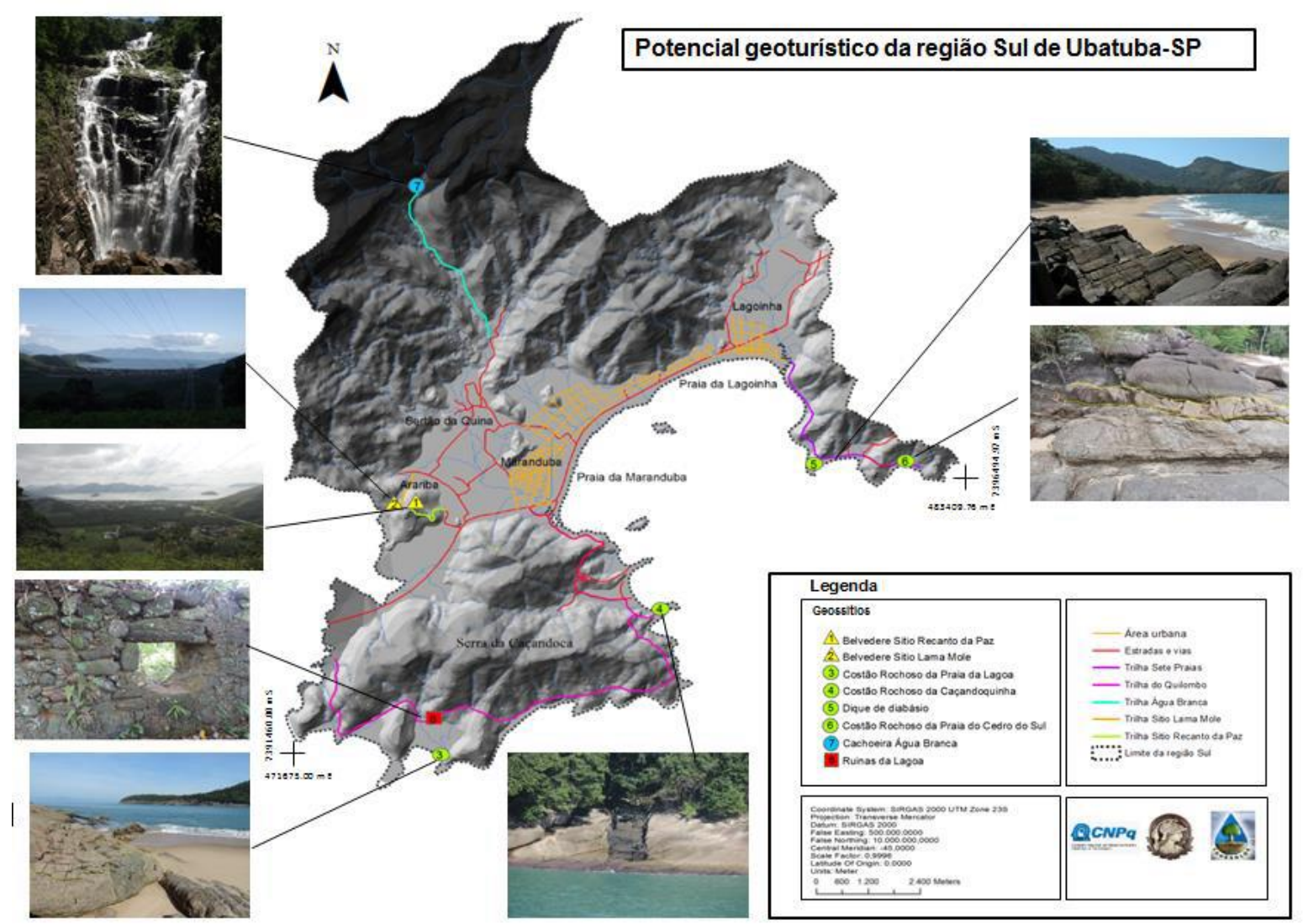

Figura 6. Potencialidade geoturística da região sul de Ubatuba-SP.

\section{CONSIDERAÇÕES FINAIS}

O artigo procurou, levando em consideração uma ampla revisão bibliográfica, abranger um tema que possui grande importância para a Geomorfologia, qual seja o de utilizar seus conhecimentos, no sentido de se poder fazer um planejamento ambiental adequado, com fins a aproveitar ao máximo os recursos naturais e, ao mesmo tempo, manter a sustentabilidade dos ecossistemas.

No que diz respeito às cidades, o crescimento desordenado, em várias partes do mundo, tem levado à degradação do meio ambiente e torna-se necessário aplicar, de forma mais efetiva os conhecimentos geomorfológicos, para que possa haver compatibilidade entre o crescimento e o equilíbrio ambiental urbano. Para se atingir esse equilíbrio é preciso que as cidades sejam planejadas, de forma que os recursos naturais sejam usados cuidadosamente, para que as gerações futuras não sejam prejudicadas. Dessa forma, os conceitos de planejamento ecológico e geomorfológico se tornam indispensáveis, para se atingir desenvolvimento sustentável das cidades. Trata-se de uma ferramenta efetiva, que objetiva o 
crescimento urbano, em harmonia com valores ecológicos, geomorfológicos, econômicos e sociais.

Esse tipo de desenvolvimento depende bastante na habilidade dos planejadores e dos ecólogos, bem como dos geomorfólogos, em descrever relações históricas ecológicas, inferidas a partir de padrões de solos e outros processos geomorfológicos do passado, e, ao mesmo tempo, compreender efeitos contemporâneos sobre o uso dos recursos naturais, na saúde dos ecossistemas.

A maioria dos planejadores e geógrafos, que refletem sobre o Antropoceno, focam na definição de limiares, os quais uma nova era está começando. Temos que pensar nas gerações futuras, devido ao fato de que vão sofrer boa parte dos custos ambientais, da utilização dos combustíveis fósseis, no presente. Sob o ponto de vista das transições que o Antropoceno representa, isso cria necessidade urgente para avaliar os objetivos do planejamento ambiental urbano, ainda mais se levarmos em conta os riscos de elevação do nível do mar.

Dessa forma, procurou-se valorizar o trabalho dos geomorfólogos, no sentido de utilizarem os conceitos já consagrados por essa ciência, bem como alguns exemplos de aplicações que podem ser feitas, tanto nas áreas rurais, como urbanas. Temas mais recentes, como geodiversidade, geoturismo e geoconservação não poderiam deixar de ser aqui abordados, porque estão intimamente relacionados com a Geomorfologia e como pode contribuir no planejamento ambiental para que se possa desenvolver o geoturismo, mantendo a geoconservação dos locais explorados.

Finalmente, existe um grande número de razões pelas quais os geomorfólogos queiram, cada vez mais, se envolver na formulação de políticas públicas, onde seus conhecimentos possam promover o bem-estar social, bem como o desenvolvimento sustentável das áreas atingidas. Uma questão central permanece: quais são as estratégias para envolvimento nas políticas públicas? Tem sido demonstrado, através de uma infinidade de trabalhos científicos, o papel da Geomorfologia no planejamento ambiental. Apesar de convincente para os cientistas, nem sempre os planejadores seguem as diretrizes apresentadas pelos geomorfólogos e outros pesquisadores. As evidências científicas podem ser rejeitadas pelos planejadores, sem se importarem com a qualidade dos dados e dos resultados atingidos. No entanto, em algumas situações esses trabalhos científicos têm sido utilizados, no planejamento ambiental, na maioria das vezes, com resultados bem positivos. A comunidade científica tem papel fundamental em convencer os planejadores, da importância dos dados gerados com suas pesquisas, para que sejam aplicados de maneira organizada, no sentido de 
que os recursos naturais sejam explorados e novas áreas sejam ocupadas, sem causar danos ambientais, que têm sido comuns há várias décadas.

\section{REFERÊNCIAS}

Abrahams, A.D. (1986). Hillslope Processes. Londres, Allen e Unwin, 416p.

Alcántara-Ayala, I. (2010). Geomorphology and disaster prevention. In: Geomorphological Hazards and Disaster Prevention. Eds. Iracema Alcántara-Ayala and Andrew Goudie, Cambridge University Press, Inglaterra, pp. 269-281.

Brilha, J. B. R. (2005). Patrimônio geológico e geoconservação: a conservação da natureza na sua vertente geológica. São Paulo: Palimage, 190p.

Brilha, J.B.R. (2016). Inventory and quantitative assessment of geosites and geodiversity sites: a review. Geoheritage, v. 8, no. 2, 119-134.

Cooke, R.U. e Doornkamp, J.C. (1977). Geomorphology in Environmental Management An Introduction. Oxford, Oxford University Press, 413p.

Cooke, R.U. e Doornkamp, J.C. (1990). Geomorphology in Environmental Management An Introduction. Oxford, Oxford University Press, 2a edição, 410p.

Crozier, M. e Glade, M. (2010). Hazard assessment for risk analysis and risk management. In: Geomorphological Hazards and Disaster Prevention. Eds. Iracema Alcántara-Ayala and Andrew Goudie, Cambridge University Press, Inglaterra, pp. 221-232.

Dowling, R. K. (2010). Geotourism's global growth. Geoheritage, v. 3, n. 1, 1-13.

Farsani, N. T., Coelho, C. O. A., Costa, C. M. M. (2012). Geotourism and Geoparks as Novel Strategies for Socio-economic Development in Rural Areas. Int. J. Tourism, v. 13, 6881.

Farsani, N. T., Coelho, C. O. A., Costa, C. M. M. Amrikzemi, A. (2014). Geo-knowledge Management and Geoconservation via Geoparks and Geotourism. Geoheritage, v. 6,185-192.

Fullen, M.A. e Catt, J.A. (2004). Soil Management - Problems and Solutions. Londres, Arnold Publisher, 269p.

Godinho, R. G., Cristóvão, C. A. M., Simon, A. P.; Orsi, M. L; Oliveira, I. J. (2011). Geomorfologia e Turismo no município de Pirenópolis (GO). Caminhos de Geografia, v. 12, 73-84.

Goudie, A. (1990). The Human Impact on the Natural Environment. Oxford, Basil Blackwell Ltda., 388p. 
Goudie, A. e Viles, H. (1997). The Earth Transformed - An Introduction to Human Impacts on the Environment. Oxford, Basil Blackwell Ltda., 276p.

Gray, M. (2004). Geodiversity - Valuing and Conserving Abiotic Nature. New York: John Wiley and Sons.

Guerra, A.J.T. e Marçal, M.S. (2015). Geomorfologia Ambiental. Editora Bertrand Brasil, Rio de Janeiro, $7^{\mathrm{a}}$ edição, 189p.

Guerra, A.J.T., Fullen, M.A., Jorge, C.O.M., Bezerra, J.F.R., Shokr, M.S. (2017). Slope processes, mass movement and soil erosion: a review. Pedosphere, 27(1), 27-41.

Haigh M. J. (1989). Review: Geomorphology in Environmental Planning by J. M. Hooke (Ed.). Transactions of the Institute of British Geographers, Vol. 14, No. 2, pp. 241-242.

Haughton, G. (2017). Environmental planning. In: The International Encyclopedia of Geography. Orgs. D. Richardson, N. Castree, M. F. Goodchild, A. Kobayashi, W. Liu, e R. A. Marston. John Wiley \& Sons, Chichester, Inglaterra, pp. 1-7.

Hill, K. (2016). Climate change: implications for the assumptions, goals and methods of urban environmental planning. Urban Planning, v. 1, no. 4, 103-113.

Hooke, J.M. (1988). Introduction: frameworks for interaction. In: Geomorphology in Environmental Planning. Ed. Janet M. Hooke, John Wiley and Sons, Chichester, Inglaterra, pp. 3-15.

Hose, T. A. (1995). Selling the Story of Britain's Stone. Environmental Interpretation, v. 2, $16-17$.

Hose, T.A. (2012). 3G's for Modern Geotourism. Geoheritage, v. 4, n. 1-2, 7-24.

Hufschmidt, G. e Glade, T. (2010). Vulnerability analysis in geomorphic risk assessment. In: Geomorphological Hazards and Disaster Prevention. Eds. Iracema Alcántara-Ayala and Andrew Goudie, Cambridge University Press, Inglaterra, pp. 233-243.

Jorge, M.C.O. (2017). Potencial geoturístico e estratégias de geoconservação em trilhas situadas na região sul do município de Ubatuba - SP. Tese de doutorado, Programa de Pósgraduação em Geografia, Universidade Federal do Rio de Janeiro.

Jorge, M.C.O. e Guerra, A.J.T. (2016). Geodiversidade, Geoturismo e Geoconservação: Conceitos, Teorias e Métodos. Espaço Aberto, PPGG - UFRJ, v. 6, No.1, 151-174. 
Jorge, M. C. O., Guerra, A. J. T., Fullen, M. A. (2016). Geotourism, Geodiversity and Geoconservation in Ubatuba Municipality, São Paulo State, Brazil. Geography Review, v. 29, 26-29.

Kubaliková, L. (2013). Geomorphosite assessment for geotourism purposes. Czech Journal of Tourism, v. 2, no. 2, 80-104.

Lima-e-Silva, P.P., Guerra, A.J.T. e Dutra, L.E.D. (2004). Subsídios para Avaliação Econômica de Impactos Ambientais. In: Avaliação e Perícia Ambiental. Orgs. S.B. Cunha e A.J.T. Guerra. Rio de Janeiro, Editora Bertrand Brasil, 5ª edição, 217-261.

Mansur, K. L. (2009). Projetos educacionais para a popularização das Geociências e para a geoconservação. Anuário do Instituto de Geociências, edição especial, v. 5, 63-74.

Mansur, K.L. (2010). Diretrizes para a geoconservação do patrimônio geológico do estado do Rio de Janeiro: o caso do Domínio Tectônico Cabo Frio. Tese (Doutorado em Geologia) — Instituto de Geociências, Universidade Federal do Rio de Janeiro.

Marçal, M.S. e Guerra, A.J.T. (2004). Processo de Urbanização e Mudança na Paisagem da Cidade de Açailândia (Maranhão). In: Impactos Ambientais Urbanos no Brasil. Orgs. A.J.T. Guerra e S.B. Cunha. Rio de Janeiro, Editora Bertrand Brasil, 2ª edição, 275-303.

Michael-Leiba, M., Baynes, F., Scott, G., e Granger, K. (2003). Regional landslide risk to the Cairns community. Natural Hazards, 30, 223-249.

Michael-Leiba, M., Baynes, F., Scott, G., e Granger, K. (2005). Quantitative Landslide risk assessment of Cairns, Australia. In: T. Glade, M.B. Anderson e M.J. Crozier. Landslide Hazard and Risk. Chichester, John Wiley, Inglaterra, pp. 621-642.

Mora Filho, P. S. e Ruas, L. M. S. (2008). As contribuições da Geomorfologia ambiental no campo do turismo rural: a descrição paisagística como recurso metodológico para o planejamento turístico. Revista Saber Acadêmico, n. 5, 40-49.

Moreira, J. C. (2008). Patrimônio geológico em Unidades de Conservação: atividades interpretativas, educativas e geoturísticas. Tese (Doutorado em Geografia) - Universidade Federal de Santa Catarina, Florianópolis.

Moreira, J.C. (2014). Geoturismo e interpretação ambiental. $2^{a}$ ed. Ponta Grossa: Editora UEPG.

Moreira, J.C. e Bigarella, J. J. (2008). Interpretação ambiental e Geoturismo em Fernando de Noronha. In: CASTILHO, C. J. M; VIEGAS, J. M. (Orgs.). Turismo e práticas socioespaciais: múltiplas abordagens e interdisciplinaridades. Recife: Ed. Universitária da UFPE, 171-192. 
Morgan, R.P.C. (1986). Soil Erosion and Conservation. Inglaterra, Longman Group, 298p.

Morgan, R.P.C. (2005). Soil Erosion and Conservation. Inglaterra, Blackwell Publishing, 3a edição, 304p.

Nascimento, M.A.L., Mansur, K. L., Moreira, J. M. (2015). Bases conceituais para entender geodiversidade, patrimônio geológico, geoconservação e geoturismo. Revista Equador. Edição especial. Territórios brasileiros: dinâmicas, potencialidades e vulnerabilidades, Piauí, v. 3, n. 4, 48-68.

Ollier, C. (2012). Problems of geotourism and geodiversity. Quaestiones Geographicae, v. 31, n. 3, 57-61.

Palhares, J. M. e Guerra, A.J.T. (2016). Potencialidades no Município de Oiapoque, Amapá, para o Desenvolvimento do Geoturismo. Espaço Aberto (UFRJ), v. 6, p. 51-72.

Papageorgiou, M. e Gemennetzi, G. (2017). Spatial environmental planning in Athens and Thessaloniki. In: $15^{\text {th }}$ International Conference on Environmental Science and Technology, Rhodes, Grécia, 31 agosto - 2 setembro, 2017, 1-5.

Parkey J. (2015). Spatial information for environmental planning. Relatório Técnico, Anderson County Government, South Carolina, Estados Unidos, 1-4.

Perveen, S., Kamruzzaman, M.D. e Yigitcanlar, T. (2017). Developing Policy Scenarios for Sustainable Urban Growth Management: A Delphi Approach. Sustainability, 9, 1-27.

Pires, V.R.O., Garcia, M.A., Martines, M.R. e Toppa, R.H. (2016). Mapeamento do uso e ocupação da terra como subsídio para o planejamento ambiental. Ambiência Guarapuava (PR) v.12 Ed. Especial, 899 - 908.

Rangel, L.A. (2018). Geoturismo em Unidades de Conservação: a utilização de trilhas no litoral do Parque Nacional da Serra da Bocaina - Paraty - RJ. Tese de Doutorado em Geografia, Programa de Pós Graduação de Geografia, UFRJ.

Santucci, V. L. (2005) Historical Perspectives on Biodiversity and Geodiversity. Geodiversity and Geoconservation, v. 22, n. 3, 29-34. 